\title{
Análise da validade e da fidedignidade de um questionário para identificação do conhecimento conceitual sobre plano inclinado e aceleração
}

\author{
Analysis of validity and reliability of a questionnaire to assess \\ conceptual knowledge about inclined plane and acceleration
}

\author{
Rafaela Dinali Nascimento ${ }^{1}$ \\ Alessandro Damásio Trani Gomes ${ }^{2}$
}

\section{Resumo}

Discute-se, neste trabalho, a importância do estabelecimento da validade e da fidedignidade de instrumentos de coleta de dados em pesquisa no ensino de Ciências. Apresenta-se o processo de análise de um questionário misto sobre movimento acelerado e plano inclinado, aplicado a 185 alunos do Ensino Médio de uma escola pública federal. O questionário, elaborado com 8 questões, passou por processos de validação de conteúdo e preditiva. Os coeficientes alfa de Cronbach e beta de Silveira foram calculados para se determinar a consistência interna do questionário. Por meio destes processos, verificou-se sua adequação para avaliar o conhecimento conceitual de estudantes sobre os assuntos desejados. Com base na revisão da literatura, são discutidas algumas implicações para a área de pesquisa e ensino de Ciências.

Palavras chave: validade; confiabilidade; questionário.

\section{Abstract}

This paper discusses the importance of establishing the validity and reliability of data collection instruments in the research in science teaching. We present the process of analysis of a mixed questionnaire about accelerated movement and inclined plane, applied to 185 high school students of a federal public school. This eight questions questionnaire passed through the processes of content and predictive validations. Cronbach's alpha and Silveira's beta coefficients were calculated to determine the internal consistency of the questionnaire. By this process, the adequacy of the questionnaire to evaluate the conceptual knowledge of students on acceleration and inclined plane was verified. Based on the literature review, some implications were made for the research area and for science teaching.

Keywords: validation; reliability; questionnaire.

\footnotetext{
${ }^{1}$ Universidade Federal de São João del-Rei | rafaeladinali@hotmail.com

${ }^{2}$ Universidade Federal de São João del-Rei | alessandrogomes@ufsj.edu.br
} 


\section{Introdução}

Quando se deseja investigar o conhecimento conceitual de um indivíduo, a melhor técnica a ser utilizada é a chamada entrevista clínica. Por meio dela, segundo Silveira, Moreira e Axt (1986) é possível colher informações precisas sobre modos de raciocínio do aluno, permitindo chegar bem perto do que se poderia chamar de conhecimento conceitual. Contudo, ela não é apropriada para ser usada no contexto de sala de aula, visto que requer muita experiência para utilizá-la e muito tempo para aplicá-la, pois cada aluno deve ser entrevistado individualmente.

Outra forma de identificar o conhecimento conceitual é por meio da aplicação de questionários. O questionário é, sem dúvida, um dos instrumentos mais utilizados na educação e também na área de pesquisa em ensino, isso porque há uma maior facilidade em abranger um grande número de indivíduos em um tempo bem menor. Os questionários podem ser utilizados nas mais diferentes áreas, para o levantamento das mais diversas informações: opiniões, conhecimentos, identificação socioeconômica, dentre vários outros exemplos. Os questionários são construídos, basicamente, por dois tipos de questões: abertas ou fechadas. Nas questões abertas, há uma maior flexibilidade quanto à resposta, o indivíduo participante tem a liberdade de construir sua resposta e nela expor sua opinião. Nas questões fechadas não há essa liberdade. O indivíduo deve marcar aquela resposta que ele julga ser a correta, mediante seus conhecimentos e opiniões. Os questionários que são construídos com esses dois tipos de questões são chamados de mistos (AMARO; PÓVOA; MACEDO, 2004).

Segundo Piekarz et al. (2003), os questionários permitem diagnósticos relativamente rápidos e eficientes de indivíduos, apesar de haver certa perda de informação ao passar de métodos qualitativos para os quantitativos, juntamente com uma redução na confiabilidade das conclusões alcançadas sobre os indivíduos. Além disso, como todo instrumento de avaliação, a elaboração de questionários exige experiência por parte do elaborador. É necessário que o mesmo tenha amplo conhecimento do domínio teórico, defina os objetivos de cada questão e, principalmente, conheça o perfil daqueles que irão responder ao questionário (SARAIVA; SILVEIRA; STEFFANI, 2011).

Após sua elaboração, é importante que o questionário seja validado, com o objetivo de obter informações fidedignas a partir das respostas contidas nele. Ao analisar os dados de um instrumento de pesquisa, um pesquisador precisa ter a garantia de sua qualidade. Esse instrumento só trará essa garantia se possuir fidedignidade e validade suficientes. Um instrumento é fidedigno se suas medidas são acuradas e consistentes quando aplicado em tempos diferentes e ele possui validade se mede o que se propõe a medir (MOREIRA; ROSA, 2008).

O objetivo deste trabalho é apresentar a análise da validade e da fidedignidade de um questionário misto sobre movimento acelerado e plano inclinado, aplicado a 185 alunos do primeiro ano do Ensino Médio de uma escola pública federal de Belo Horizonte. Busca-se, com este estudo, contribuir para a perenidade das metodologias e análises quantitativas e ressaltar a importância e a necessidade de reflexões sobre questões relacionadas à validade e à fidedignidade dos instrumentos de coleta de dados na pesquisa em ensino de Ciências. 


\title{
A fidedignidade e validade de questionários nas pesquisas em ensino de ciências
}

Testes ou questionários de conhecimento são frequentes na pesquisa em ensino de Ciências e têm, por objetivo, mensurar o conhecimento conceitual dos indivíduos sobre determinado domínio ou área. Avaliações de alunos, professores e cursos são feitas levando-se em consideração os resultados desses testes, tão frequentes também no ambiente escolar.

Gil (2008) define questionário como a técnica de investigação composta por um conjunto de questões que são submetidas a pessoas com o propósito de obter informações sobre conhecimentos, crenças, sentimentos, valores, interesses, expectativas, aspirações, temores, comportamento etc.

Segundo Moreira (2011), não adianta o pesquisador ser cuidadoso na escolha do delineamento da pesquisa se os instrumentos de coleta de dados forem inadequados. Deve-se então, observar questões relacionadas à fidedignidade (o instrumento mede corretamente o que se propõe a medir?) e à validade (o instrumento mede outra coisa diferente daquela que se propõe a medir?) para se garantir a qualidade dos dados disponíveis para análise.

A ausência frequente de discussões sobre a validade e fidedignidade dos instrumentos e dos dados de pesquisa, bem como a validade dos resultados alcançados é apontada por Santos e Greca (2013) como um dos problemas da pesquisa na área de Ensino de Ciências na última década.

A fidedignidade de um instrumento de coleta de dados é o quão acurado são os dados produzidos no sentido de sua estabilidade, reprodutibilidade ou precisão. Pasquali (2009) também associa os termos precisão, confiabilidade, estabilidade, constância, consistência interna e equivalência ao parâmetro da fidedignidade, dependendo do tipo de técnica utilizada na coleta da informação ou da estatística utilizada para a análise dos dados coletados. Um instrumento de coleta de dados fidedignamente perfeito é tal, que se fosse aplicado duas vezes sob as mesmas circunstâncias, forneceria os mesmos resultados.

Vianna (1976, p. 145) explica de forma objetiva a importância da fidedignidade de um instrumento de medida ao afirmar que

\begin{abstract}
se um teste é aplicado ao mesmo grupo um grande número de vezes, espera-se que os resultados sejam os mesmos, desde que o grupo não se modifique. Se em cada vez que o teste for aplicado, satisfeitas determinadas condições, os escores forem diferentes para o mesmo grupo, não se poderá ter confiança no instrumento, porque não haverá consistência nas medidas.
\end{abstract}

A correlação é a ferramenta estatística básica na análise de fidedignidade de testes. O coeficiente de correlação, conforme explica Moreira (2011), é o que nos indica como duas ou mais variáveis se comportam uma em relação à outra. Este coeficiente varia de -1 , quando o crescimento de uma variável é acompanhado pelo decrescimento de outra, até +1 , quando o crescimento de uma variável é acompanhado pelo crescimento de outra, sendo que esses valores extremos indicam a perfeita correlação entre as variáveis. Quando o valor do coeficiente de correlação é próximo de zero, indica a inexistência de correlação entre as variáveis.

Segundo Silveira, Moreira e Axt (1986), a teoria psicométrica determina como condição necessária (mas não suficiente) para ser observada correlação entre duas 
variáveis, a existência de fidedignidade na medida de cada variável. Posto de outra forma, se as variáveis não apresentarem fidedignidade, então a correlação observada entre elas será nula, mesmo que a verdadeira correlação seja não nula.

Há na literatura especializada, algumas formas de se determinar a fidedignidade de um instrumento de medida (PASQUALI, 1997; GOMEZ, 1998; MOREIRA, 2011), cada qual com suas vantagens e desvantagens, aplicáveis a situações e contextos de pesquisa específicos:

- Teste-reteste: esse procedimento consiste em aplicar o mesmo teste em ocasiões diferentes e calcular a correlação. Quanto maior o coeficiente de correlação obtido entre os dados provenientes das duas exposições dos sujeitos ao mesmo conteúdo, maior a fidedignidade.

- Forma alternada: consiste em aplicar duas formas diferentes, mas equivalentes de um teste aos sujeitos e calcular a correlação.

- Método da metade ou par-ímpar: o instrumento é aplicado uma única vez a um grupo de respondentes. Entretanto, ele é dividido em duas partes equivalentes (duas metades ou itens pares e itens ímpares) de forma a separar os escores para cada respondente. Estes dois conjuntos de escores são, então, correlacionados. A partir do coeficiente de correlação obtido, pode-se determinar a estimativa de fidedignidade de Spearman-Brown (ARAÚJO; LABURÚ, 2009).

A determinação da fidedignidade de um questionário é comumente realizada, na área de pesquisa em ensino de Ciências, pela análise da consistência interna do teste. Quando um pesquisador ou um professor aplica um questionário, normalmente os escores obtidos em cada item são somados para compor um escore total para cada respondente.

A análise da consistência interna considera os valores das correlações entre cada um dos itens e as correlações entre os itens e o escore total. Considerando um questionário fidedignamente perfeito, as correlações item-item e item-total seriam todas iguais a 1,0.

Pesquisas recomendam que, para o cálculo da homogeneidade dos componentes que compõem o escore total de um questionário e a determinação da consistência interna dos itens, sejam calculados os valores dos coeficientes alfa de Cronbach e beta de Silveira (CRONBACH, 1951; SILVEIRA, 1985).

Para Moreira (2003), enquanto a fidedignidade é um pré-requisito para qualquer instrumento de pesquisa, a validade é a característica mais importante que ele deve possuir. Isto ocorre porque a validade está ligada ao relacionamento entre os dados obtidos e o propósito da pesquisa. Deste modo, validade é definida como o grau com que o instrumento realmente mede o que se propõe a medir.

$\mathrm{Na}$ área de pesquisa em ensino de Ciências, destacam-se os seguintes tipos de validade dentre os vários tipos existentes (SILVEIRA, 1993; PASQUALI, 1997; MOREIRA; ROSA, 2008):

- Validade de conteúdo: é uma das técnicas mais utilizadas para analisar questionários e entrevistas. Esta técnica verifica se o instrumento está medindo o que se propõe a medir por meio da análise da existência de razões racionais para a escolha do conteúdo do instrumento ou de uma base, lógica ou empírica, para esta escolha.

- Validade congruente ou concorrente: é determinada quando se estabelece a correlação entre os resultados da aplicação de um instrumento já validado e os resultados do instrumento que se deseja validar.

- Validade preditiva: quando o pesquisador usa os resultados obtidos com esse instrumento para fazer predições sobre o comportamento futuro daqueles que o responderam e elas forem confirmadas. 
Em uma análise dos trabalhos publicados nos últimos anos, em alguns dos principais periódicos nacionais dedicados à pesquisa no ensino em Ciências, identificamos quatro trabalhos nos quais os autores realizaram pesquisas quantitativas, discutiram e mensuraram a fidedignidade e/ou a validade dos instrumentos de coleta de dados utilizados.

Gonzales e Rosa (2014) utilizaram alfa de Cronbach como medida da fidedignidade do teste destinado a identificar a diferença na aprendizagem de conceitos de circuitos elétricos entre aqueles alunos que utilizaram, ou não, um ambiente virtual.

Talim (2004) também utilizou o coeficiente alfa de Cronbach para a validação da consistência interna dos itens de uma escala tipo Likert para identificar a atitude de estudantes do Ensino Médio em relação à Física.

Rocha e Ricardo (2013) utilizaram um teste, também construído em escala Likert, para aferição das crenças de autoeficácia ligadas a Física Moderna e Contemporânea. Segundo eles, as crenças de autoeficácia dos professores podem nos auxiliar a compreender como eles conduzem suas ações em sala de aula. Para demonstrar a validade do instrumento de pesquisa utilizado, os autores realizaram processos de validação de conteúdo, de critério e de constructo.

Araújo e Laburú (2009) descreveram o processo de validação e confiabilidade da escala de opiniões de professores para a seleção de experimentos em Química. A escala Likert criada foi submetida à validação de conteúdo, na qual foram utilizadas as técnicas do pré-teste e teste-piloto até a versão final aprovada por peritos da área. Os autores também utilizaram as técnicas da forma paralela e Spearman para verificarem a estabilidade do instrumento no tempo.

\section{Aspectos metodológicos}

A pesquisa relatada neste trabalho faz parte de um programa de pesquisa mais amplo que visa identificar os fatores que influenciam no desempenho de estudantes durante a realização de atividades investigativas. Autores como Penner e Klahr (1996) e Schauble (1996) sugerem que o conhecimento conceitual sobre o domínio teórico da atividade é um fator fundamental e que exerce profunda influência sobre as decisões e estratégias dos estudantes durante as atividades.

O objetivo da elaboração do questionário foi, portanto, o de identificar o conhecimento conceitual dos participantes. O tema escolhido foi o plano inclinado, por sua importância para o ensino de Física, para a história da Ciência (BRITO, 1985; WÖRNER, 2012) e por ser um dos temas das atividades investigativas desenvolvidas.

\section{Sujeitos da pesquisa}

A coleta de dados ocorreu em uma escola de Ensino Médio e Técnico da rede federal de ensino de Belo Horizonte. Dos 191 estudantes matriculados no $1^{\circ}$ ano, 185 responderam ao questionário. Esses alunos eram divididos em sete turmas e tinham idades variando entre 14 e 18 anos e média de 16,1 anos.

\section{Instrumentos de pesquisa}

Foi elaborado um questionário contento uma questão aberta, duas associativas e cinco de múltipla escolha sobre movimento acelerado e plano inclinado (Figura 1). Algumas 
questões foram elaboradas para a pesquisa, outras retiradas de livros de Física ou provas de ingresso em universidades, algumas com pequenas modificações. Para Nogueira (2002), a presença de questões abertas é importante e possibilita explorar todas as possíveis respostas a respeito dos conceitos abordados.

1) O que você entende por um movimento acelerado?

2) Considere uma bolinha se movimentando conforme as figuras abaixo. Em cada caso, estão representados os vetores velocidade e aceleração. Associe o desenho à descrição do tipo de movimento:

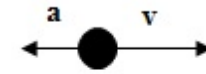

( I)

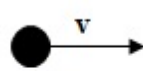

( II )

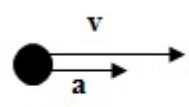

( III)
Movimento Uniforme;

Movimento Uniformemente Acelerado; Movimento Uniformemente Retardado;

3) Marque U para a situação na qual o movimento descrito é um exemplo de movimento retilíneo uniforme, UA, se o exemplo for de movimento retilíneo uniformemente acelerado e UR se a situação exemplificar um movimento retilíneo uniformemente retardado (Despreze a resistência do ar).

Uma bola lançada verticalmente para cima até atingir o ponto máximo; atrito;

Uma bola descendo uma rampa inclinada sem

A bola de boliche durante seu movimento antes da colisão com os pinos;

Um carro em alta velocidade, parando em um sinal vermelho;

4) Um carro desce por uma rua inclinada, continua movendo-se por uma rua horizontal e, em seguida, colide com um poste. Ao investigar o acidente, um perito de trânsito verificou que o carro tinha um vazamento de óleo que fazia pingar no chão gotas em intervalos de tempo iguais. Ele verificou também que a distância entre as gotas era constante na rua inclinada e diminuía gradativamente na rua horizontal.

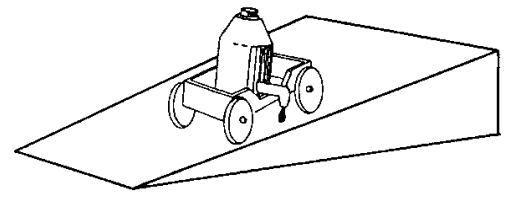

Desprezando a resistência do ar, o perito pode concluir que o carro:

a) vinha acelerando na descida e passou a frear na rua plana.

b) descia com velocidade constante a rua inclinada e passou a frear na rua plana.

c) vinha freando desde o trecho no plano inclinado.

d) não reduziu a velocidade até o choque.
5) Considere uma esfera descendo uma rampa inclinada. Assinale a alternativa falsa.

a) $\mathrm{O}$ coeficiente de atrito dependerá apenas dos materiais da esfera e da rampa.

b) A aceleração da esfera aumenta a medida que a esfera desce a rampa.

c) Se aumentarmos a inclinação da rampa, a velocidade final da esfera será maior.

d) A cada segundo, a velocidade da esfera aumenta sempre de um mesmo valor.

6) Suponha que tenhamos um carrinho descendo uma rampa sem atrito. Fixado a ele, há um marcador que deixa marcas sobre a rampa em intervalos iguais de tempo. Qual das figuras abaixo, melhor representa as marcas deixadas por esse carrinho ao descer a rampa?
a. $\quad \cdot \quad$
b. $\because \cdot \cdots$
c. $\cdots$
d. $\longdiv { \cdots }$
e. $\cdot \cdots$

Os enunciados das questões 7 e 8 referem-se ao movimento de uma bola abandonada em um plano inclinado no instante $\mathrm{t}=0 \mathrm{~s}$.
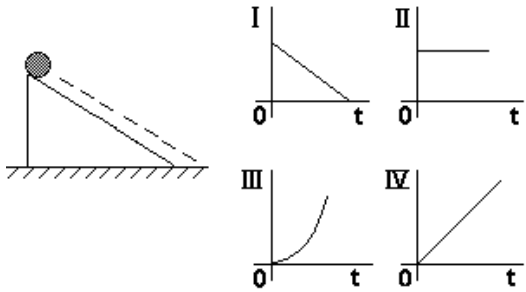

7) O gráfico que melhor representa a distância percorrida pela bola durante o movimento é:
a) I
b) II
c) III
d) IV

8) O gráfico que melhor representa o módulo da velocidade da bola durante o movimento é:
a) I
b) II
c) III
d) IV

Figura 1: Questionário sobre plano inclinado e aceleração.

O questionário foi submetido a um processo de validação de conteúdo antes de ser aplicado, seguindo procedimentos similares aos de Oda (2012). Seis professores, com pelo 
menos curso de Especialização em ensino de Ciências/Física e familiarizados com pesquisa em ensino de Ciências, avaliaram o questionário, tendo em vista sua adequação para o levantamento do conhecimento dos estudantes sobre o tema. Durante o processo de avaliação, os professores atribuíram uma nota que variava entre zero (se a questão deveria ser excluída) e três (se a questão era muito adequada para identificar o conhecimento conceitual do aluno sobre o assunto). Na tabela 1 estão representados os tipos, juntamente com as notas mínimas, máximas e a média das notas atribuídas pelos professores para cada questão.

Tabela 1: Características do questionário sobre plano inclinado e movimento acelerado.

\begin{tabular}{c|c|c|c|c|c|c|c|c}
\hline Questões & 1 & 2 & 3 & 4 & 5 & 6 & 7 & 8 \\
\hline $\begin{array}{c}\text { Tipo da } \\
\text { questão }\end{array}$ & $\mathbf{A b}$ & Ass & Ass & $\mathbf{M e}$ & $\mathbf{M e}$ & $\mathbf{M e}$ & $\mathbf{M e}$ & $\mathbf{M e}$ \\
\hline Nota mínima & 2 & 2 & 2 & 2 & 2 & 2 & 2 & 2 \\
\hline Nota máxima & 3 & 3 & 3 & 3 & 3 & 3 & 3 & 3 \\
\hline Nota média & 2,7 & 2,7 & 2,5 & 2,2 & 2,7 & 2,8 & 2,5 & 2,2 \\
\hline
\end{tabular}

Legenda: Ab: aberta ou dissertativa | Me: múltipla escolha | Ass: associativa.

Pode-se observar que questão alguma recebeu nota zero ou um e a nota média de todas as questões que compunham o questionário foi maior ou igual a 2,2, o que indica que, de uma forma geral, os professores consultados aprovaram o questionário e entenderam que ele pode ser um instrumento de pesquisa para identificar o conhecimento conceitual sobre plano inclinado e movimento acelerado pertinente à atividade investigativa, que os estudantes realizariam em seguida.

O tempo de 100 minutos foi suficiente para os alunos responderem ao questionário e realizarem a atividade proposta. Também foram obtidas, com a autorização da direção da escola, junto aos quatro professores das turmas do primeiro ano do Ensino Médio, as notas dos alunos referentes às três provas trimestrais realizadas no ano. As notas das provas trimestrais também foram utilizadas como indicativo do conhecimento conceitual dos alunos em Física, pois essas provas eram as mesmas para todos os alunos e eram elaboradas e corrigidas por uma mesma equipe de professores.

\section{Análise da validade e da fidedignidade do questionário}

Para a sequência da análise da validade, fidedignidade e o resultado geral dos estudantes, foram realizados os processos de correção e de atribuição de notas às respostas. As questões de múltipla escolha foram corrigidas de forma dicotômica, sendo atribuído o valor de um ponto caso respondente acertasse a questão e zero, em caso de erro.

Para a questão 1 , aberta, o processo foi mais complexo. Durante a correção inicial, foi atribuído 0,1 ou 2 pontos às respostas dos alunos. Basicamente, atribuiu-se um ponto se o aluno respondeu que o movimento acelerado é aquele no qual há um aumento da velocidade do corpo; e dois pontos se ele afirmou que o movimento acelerado é aquele no qual ocorre uma variação da velocidade, podendo, portanto, aumentar ou diminuir a velocidade do corpo. A questão foi corrigida por dois pesquisadores de forma independente e depois as notas atribuídas foram checadas. Houve uma percentagem de concordância de $95 \%$. Os casos de divergência foram resolvidos por consenso entre os 
corretores. Após esse processo, houve a conversão da nota da questão para a escala de 0 a 1.

Para as questões 2 e 3 que são associativas, a cada associação correta foi atribuída a nota de 0,33 e 0,25 respectivamente. Após a correção, obteve-se um escore total para cada respondente, somando-se as notas obtidas em cada questão. Dessa forma, os escores dos estudantes variaram entre 0 e 8 pontos. Na tabela 2 estão os dados estatísticos básicos referentes ao questionário.

Tabela 2: Dados estatísticos do questionário.

\begin{tabular}{c|c}
\hline Dados & Valores \\
\hline Média & 4,9 \\
\hline Desvio Padrão & 1,8 \\
\hline Mediana & 5,0 \\
\hline Moda & 6,0 \\
\hline Mínimo & 0,3 \\
\hline Máximo & 8,0 \\
\hline Curtose & $-0,85$ \\
\hline Assimetria & $-0,12$ \\
\hline \multirow{2}{*}{ Quartis } & 3,5 \\
\cline { 2 - 2 } & 5,0 \\
\cline { 2 - 2 } & 6,4 \\
\hline
\end{tabular}

A média geral dos alunos foi 4,9, o que corresponde a $61 \%$ do total. Um aluno obteve o escore mínimo de 0,3 , enquanto nove alunos obtiveram o escore máximo. A proximidade entre a média e a mediana e os baixos valores obtidos para a curtose e assimetria indicam que a distribuição dos escores é próxima à normalidade.

$\mathrm{Na}$ tabela 3 estão as percentagens de acerto e o índice de discriminação das oito questões, calculados de acordo com recomendações de Moreira e Rosa (2008). O índice de discriminação mede, basicamente, o quanto cada item distingue sujeitos de desempenho superior e desempenho inferior. É desejável então que os testes tenham um alto índice de discriminação. Um item que apresenta um índice de discriminação alto indica que quem acertou o item, em média, obteve um bom desempenho no teste. Ao contrário, um item que apresenta índice de discriminação baixo indica que o item não avaliou corretamente os estudantes, pois não há relação entre o sucesso no item e o consequente sucesso no teste. O seu cálculo envolve a diferença entre a proporção de acertos entre os indivíduos de desempenho superior e inferior no teste. O grupo de desempenho inferior foi composto por $27 \%$ dos alunos que obtiveram escores abaixo ou iguais a 3,5 (primeiro quartil). O grupo de desempenho superior foi formado pelos $25 \%$ dos alunos que obtiveram escores acima de 6,4 (terceiro quartil).

Tabela 3: Dados sobre as questões do questionário.

\begin{tabular}{c|c|c|c|c|c|c|c|c}
\hline Questões & $\mathbf{1}$ & $\mathbf{2}$ & $\mathbf{3}$ & $\mathbf{4}$ & $\mathbf{5}$ & $\mathbf{6}$ & $\mathbf{7}$ & $\mathbf{8}$ \\
\hline Percentagem de acerto & $62 \%^{3}$ & $95 \%^{3}$ & $83 \%^{3}$ & $30 \%$ & $28 \%$ & $75 \%$ & $51 \%$ & $64 \%$ \\
\hline Índice de discriminação & 0,55 & 0,16 & 0,56 & 0,70 & 0,61 & 0,62 & 0,94 & 0,72 \\
\hline Correlação item-total & 0,60 & 0,28 & 0,52 & 0,54 & 0,56 & 0,58 & 0,73 & 0,59 \\
\hline
\end{tabular}

Não foi possível a divisão dos grupos de estudantes em proporções fixas. Segundo Vianna (1976), estas proporções podem, e às vezes precisam ser aproximadas, porque é

\footnotetext{
${ }^{3}$ Para as questões 1, 2 e 3 são apresentados os valores das médias dos respondentes.
} 
necessário estabelecer escores de corte, para distinguir quem pertence a um grupo ou outro e fazer aproximações. Dificilmente se consegue formar os dois grupos com a proporção de sujeitos recomendada. O grupo inferior, por exemplo, poderia apresentar ocasionalmente 25 ou 33\%, sem prejuízo para a análise dos resultados. O percentual utilizado dependerá da nota de corte escolhida para divisor dos grupos.

As porcentagens de acerto das questões variaram entre $28 \%$ e $95 \%$ e os índices de discriminação, entre 0,16 e 0,94. Seguindo os critérios encontrados em Silva (1992), podese dizer que o questionário foi composto por uma questão de baixa discriminação e as demais de descriminação elevada. Em termos de dificuldade (evidenciada pela percentagem de acerto), duas questões podem ser consideradas muito fáceis, três fáceis, uma questão de dificuldade média e duas questões difíceis.

Calculamos os coeficientes alfa de Cronbach e o beta de Silveira. Os valores obtidos, 0,68 e 0,78 respectivamente, podem ser considerados razoavelmente elevados, o que, juntamente com os valores das correlações item-total da tabela 3 atestam positivamente sobre a consistência interna e a fidedignidade do questionário elaborado (SILVEIRA,1993).

Ao longo do ano letivo, os alunos realizaram três provas trimestrais no valor de doze pontos cada. As notas obtidas por cada aluno nessas provas foram somadas e transformadas em percentual, valor que, de agora em diante, é denominado apenas como Trimestral. Os resultados de todos os 191 alunos matriculados são apresentados na tabela 4.

Tabela 4: Resultados da Trimestral $(n=191)$.

\begin{tabular}{c|c}
\hline Dados & Valores \\
\hline Média & 58,9 \\
\hline Desvio Padrão & 17,3 \\
\hline Mediana & 58,1 \\
\hline Nota mínima & 18,1 \\
\hline Nota máxima & 96,1 \\
\hline Correlação Trimestral - Questionário & 0,67 \\
\hline
\end{tabular}

Busca-se, com a utilização da Trimestral, determinar a validade preditiva do questionário elaborado. Espera-se que o aluno que obteve um escore elevado no questionário, também tenha obtido uma nota elevada na Trimestral. A tabela 4 exibe a correlação entre as notas dos alunos na Trimestral e o escore obtido no questionário. A correlação obtida, com significância menor que 0,01 , é satisfatória, corroborando a consideração de que os resultados obtidos pelos estudantes na Trimestral e no questionário estão correlacionados.

\section{Análise e discussão dos resultados do questionário}

A análise das respostas dos estudantes e os resultados do questionário são apresentados a seguir. A primeira questão é dissertativa e solicita ao estudante escrever o que ele compreende ser um movimento acelerado. Para efeito de exemplificação, algumas respostas foram transcritas e as notas atribuídas na escala inicial de 0,1 ou 2 pontos:

\section{Nota 0}

"Entendo por movimento acelerado, um movimento que se move com certa velocidade rápida".

"O movimento acelerado é aquele movimento que em um trecho, o objeto se mantém mais acelerado". 


\section{Nota 1}

"Um movimento no qual a velocidade de um corpo aumenta devido à aplicação de uma força no corpo."

"É um movimento em que a velocidade vai sempre aumentando."

\section{Nota 2}

"Um movimento que possui uma variação de sua velocidade ao longo do seu percurso."

"Movimento acelerado é o movimento de algo que não tem sua velocidade constante. Se a velocidade aumenta, o movimento é acelerado. Mas se a velocidade diminui, o movimento é retardado."

A média de $62 \%$ pode ser considerada satisfatória. Pesquisas indicam que alunos apresentam dificuldades em compreender o conceito de aceleração (McDERMOTT, 1984; DRIVER et al., 1994; GIORGI; CONCARI; POZZO, 2004). Para 41 respostas (22\%) foram atribuídas nota 0 , para 57 (31\%), nota 1 e para outras 87 respostas (47\%) foram atribuídas nota 2.

A questão 2 pode ser considerada a questão mais fácil do questionário. Ela foi a questão mais acertada e com o menor índice de discriminação. Dos 185 respondentes, 173 acertaram todas as associações. Percebe-se, portanto, que o grupo de estudantes pesquisado compreende a relação entre os vetores velocidade e aceleração para cada tipo de movimento considerado, apesar da relativa dificuldade de conceptualização na primeira questão.

$\mathrm{Na}$ questão 3 são apresentados alguns exemplos de movimentos triviais do cotidiano e é solicitado que os alunos reconheçam o tipo de movimento de acordo com a aceleração. Os alunos não tiveram grandes problemas para responder a essa questão. Apenas dois alunos a erraram completamente. Por outro lado, 109 alunos (59\% do total) acertaram as quatro associações.

Tabela 5: Respostas dos alunos nas questões de múltipla escolha.

\begin{tabular}{c|c|c|c|c|c}
\hline Opções & Quest.4 & Quest.5 & Quest.6 & Quest.7 & Quest.8 \\
\hline a & 17 & 74 & 21 & 31 & 6 \\
\hline b & 97 & 52 & 140 & 7 & 7 \\
\hline c & 57 & 14 & 6 & 95 & 54 \\
\hline d & 15 & 46 & 13 & 53 & 119 \\
\hline e & ---- & ---- & 6 & ---- & ---- \\
\hline
\end{tabular}

NOTA: a resposta assinalada é a mais adequada.

$\mathrm{Na}$ tabela 5 estão as distribuições das respostas dos estudantes para cada questão de múltipla escolha do questionário. Observando a tabela, nota-se que os alunos apresentaram maiores dificuldades nas questões 4 e 5 . Nas demais, a opção correta foi marcada pela maioria dos alunos.

Para se resolver a questão 4, além de conhecimento específico sobre o domínio teórico abordado, exige-se também uma habilidade de leitura e interpretação, o que deve ter contribuído para dificultar a análise dos alunos. Marcas de óleo no asfalto igualmente espaçadas, em uma rua inclinada, só podem ser produzidas se o carro estiver freando. A opção (b) foi a mais marcada e afirma que o carro começou a frear apenas quando chegou ao trecho plano.

A questão 5 foi a questão com o menor percentual de acerto do questionário. Isso se deve ao fato de que ela envolve, numa mesma questão, vários aspectos chaves do movimento acelerado executado num plano inclinado, o que deve ter dificultado sua 
resolução. Além disso, apesar da palavra 'falsa' estar escrito em negrito, ela pode ter passado despercebida à leitura dos estudantes, o que também pode ter dificultado a escolha pela resposta adequada. A opção (a) foi mais a mais marcada, indicando uma dificuldade conceitual sobre o coeficiente de atrito. A opção (d) foi marcada por $25 \%$ dos respondentes. Nela, está embutida a definição de movimento uniformemente acelerado, e a consciência de que uma esfera descendo uma rampa trata-se de um dos exemplos desse tipo de movimento.

Os alunos, em geral, não tiveram grandes dificuldades para responderem à questão 6 . Ela foi a questão de múltipla escolha com maior índice de acerto do questionário. Acreditase que as opções contribuíram para que os alunos alcançassem a resposta correta. Os distratores representados pelas opções (c) e (e) possuem pouca atratividade. Além da opção correta, a opção marcada por $11 \%$ dos respondentes foi a letra (a), que é justamente o contrário da resposta correta e representaria um movimento retardado.

A questão 7 aborda o movimento de uma esfera que percorre um plano inclinado e solicita aos estudantes marcarem a opção que melhor representa o gráfico da distância percorrida durante o movimento. A opção correta foi escolhida pela maioria. Porém, um número significativo de alunos também optou pelas opções (a) e (d). A atratividade da opção (a) pode ser justificada pela semelhança da curva do gráfico e do plano inclinado. Essa é uma tendência comum entre os alunos com maiores dificuldades de compreensão gráfica. Já a opção (d), apresenta um gráfico cujo aspecto é muito comum ao estudante do primeiro ano do Ensino Médio, seja na Matemática, seja na Física. Essa questão teve o maior índice de discriminação entre as questões do questionário e também a maior correlação item-total. Isso indica que, no geral, os alunos que obtiveram as melhores notas no questionário tenderam a acertar essa questão. E, ao contrário, os alunos que tiveram um desempenho ruim tenderam a errá-la. Tal fato pode parecer trivial, mas não o é. $O$ mesmo não pode ser dito para a questão 2, por exemplo, cujos índice de discriminação e correlação item-total foram baixos. Isso significa que a questão 2 não discrimina ou diferencia os alunos que foram bem ou mal no questionário, pois em ambos os casos, os alunos tenderam a acertar a questão, uma vez que seu índice de acerto foi muito elevado.

A questão 8 aproveita o mesmo enunciado da questão 7, mas pergunta sobre o gráfico que melhor representa o módulo da velocidade da bola durante o movimento. A opção correta é representada pelo gráfico da letra (d), marcada pela maioria. Outros $29 \%$ dos estudantes marcaram erroneamente a opção (c). Desses, boa parte fez confusão entre os gráficos da distância percorrida e da velocidade e inverteram as respostas entre as questões 7 e 8, errando ambas.

A análise das respostas dos alunos contribui para a identificação de concepções inadequadas sobre o movimento no plano inclinado. Identificar e reconhecer a existência de tais concepções é importante para que se possa aprimorar não somente a abordagem em sala de aula, mas também para auxiliar na elaboração de novas atividades e materiais didáticos que contribuam para a sofisticação do conhecimento conceitual dos alunos sobre o assunto abordado. 


\section{Considerações finais}

O processo de validação e análise da confiabilidade do instrumento de pesquisa realizado de acordo com as técnicas recomendadas pela literatura da área foi satisfatório. Diante do exposto, percebe-se que a elaboração e a validação de questionários para a utilização em pesquisa ou sala de aula não são processos triviais.

Conforme foi descrito, há várias maneiras de se calcular a validade e fidedignidade de um instrumento de pesquisa. O questionário elaborado passou por dois processos de validação (de conteúdo e preditiva). A fidedignidade do instrumento foi verificada pelos cálculos dos coeficientes alfa de Cronbach e beta de Silveira.

O questionário elaborado teve como objetivo a identificação do conhecimento conceitual de estudantes sobre plano inclinado e movimento acelerado. Pretende-se que este instrumento possa ser utilizado também por professores e outros pesquisadores interessados em identificar o conhecimento de alunos sobre o mesmo tema, uma vez que o questionário foi testado em um número razoável de alunos e foram obtidas fortes evidências de sua validade e fidedignidade.

A discussão sobre a validade e a fidedignidade dos instrumentos de pesquisa deveria estar presente em todos os trabalhos empíricos publicados. Porém, foi verificada a relativa escassez dessa discussão nos artigos publicados nos principais periódicos nacionais da área de pesquisa em ensino de Ciências, o que nos faz pensar nas limitações das considerações e inferências feitas pelos autores a partir dos dados produzidos por instrumentos de pesquisa que não passaram por esses processos. Tentou-se, neste trabalho, superar essa limitação identificada na área. Mais pesquisas que demonstrem processos diversos de validação de diferentes tipos de instrumentos de pesquisas são fundamentais e podem contribuir para aumentar o rigor das publicações na área da pesquisa em ensino de Ciências.

\section{Referências}

AMARO, A.; PÓVO, A.; MACEDO, L. A arte de fazer questionários. Mestrado em Química para o Ensino. Dissertação de Mestrado. Faculdade de Ciências da Universidade do Porto, 2004.

ARAÚJO, N. R. S.; LABURÚ, C. E. Uma análise da validação e confiabilidade da escala de opiniões da seleção de experimentos de química (EOSEQ). Ensaio: Pesquisa em Educação em Ciências, v. 11, n. 2, p. 177-196, 2009.

BRITO, A. S. O plano inclinado: um problema desde Galileu. Caderno Brasileiro de Ensino de Física, V. 2, n. 2, p. 57-63, 1985.

CRONBACH, L. J. Coefficient Alpha and the Internal Structure of Tests. Psychometrika, 16, 297-334, 1951.

DRIVER, R.; SQUIRES, A.; RUSHWORTH, P.; ROBINSON, V. W. Making sense of secondary science: research into children's ideas. London: Routledge, 1994. $210 \mathrm{p}$.

GIL, A. C. Métodos e Técnicas de Pesquisa Social. 6 ed. São Paulo: Atlas, 2008.

GIORGI, S.; CONCARI, S.; POZZO, R. Un estudio sobre las investigaciones acerca de las ideas de los estudiantes en fuerza y movimiento In: Encontro Nacional de Pesquisa em Educação em Ciências, IV., 2003, Bauru, SP. Atas...

GOMEZ, A. G. Procedimientos Empíricos para Estimar la Precisión de las Puntuaciones Proporcionadas por los Tests. In: MUÑIZ, J. Teoría Clásica de los Tests. Madrid: Pirâmide, 1998, 392

p. Disponível em: <http://www.ugr.es/ andreito/tema6.doc>. Acesso em: 20 jun. 2016. 
GONZALES, E. G.; ROSA, P. R. Aprendizagem significativa de conceitos de circuitos elétricos utilizando um ambiente virtual de ensino por alunos da Educação de Jovens e Adultos. Investigações em Ensino de Ciências, v. 19, n. 2, p. 477-504, 2014.

MCDERMOTT, L. C. Research on conceptual understanding in mechanics. Physics Today, v. 37, n. 7, p. 24-32, 1984.

MOREIRA, M. A. Metodologias de pesquisa em ensino. São Paulo: Editora Livraria da Física, 2011, 234p.

MOREIRA, M. A. Pesquisa em ensino: aspectos metodológicos. Actas del PIDEC: Programa internacional de Doctorado em Enseñanza de las Ciencias, v. 5, p. 101-136, 2003.

MOREIRA, M. A.; ROSA, P. R. S. Uma introdução à pesquisa quantitativa em Ensino. Porto Alegre: Ed. dos Autores, 2008.

NOGUEIRA, R. Elaboração e Análise de Questionário: Uma revisão da literatura básica e a aplicação dos conceitos a um caso real. Rio de Janeiro. UFRJ/ COPPEAD. 2002.

ODA, W. Y. Concepções de saúde entre docentes de Biologia: um instrumento investigativo. Amazônia: Revista de Educação em Ciências e Matemáticas, v. 8, n. 16, p.99-109, 2012.

PASQUALI L. Psicometria: teoria e aplicações. Brasília: Editora UNB, 1997, 289 p.

PASQUALI, L. Psicometria. Revista da Escola de Enfermagem da USP, 43(Esp.), 992-999, 2009.

PENNER, D. E.; KLAHR, D. The Interaction of Domain-Specific Knowledge and Domain-General Discovery Strategies: A Study with Sinking Objects. Child Development, v.67, p. 2709-2727, 1996.

PIEKARZ, A. H. et al. Adaptação e Validação de um Teste de Diagnóstico de Concepções Espontâneas em Mecânica. Simpósio Nacional de Ensino de Física, Curitiba, PR, XV, 2003, Atas...

ROCHA, D. M.; RICARDO, E. C. As crenças de autoeficácia de professores de Física: um instrumento para aferição das crenças de autoeficácia ligadas a Física Moderna e Contemporânea. Caderno Brasileiro de Ensino de Física, v. 31, n. 2, p. 333-364, 2013.

SANTOS, F. M. T.; GRECA, I. M. Metodologias de pesquisa no ensino de ciências na América Latina: como pesquisamos na década de 2000. Ciência \& Educação, v. 19, n. 1, p. 15-33, 2013.

SARAIVA, M. F. O.; SILVEIRA, F. L.; STEFFANI, M. H. Concepções de estudantes universitários sobrea as fases da Lua. Revista Latino-Americana de Educação em Astronomia - RELEA, Limeira, v.1, n. 11, p. 63-80, 2011.

SCHAUBLE, L. The Development of Scientific Reasoning in Knowledge-Rich Contexts. Developmental Psychology, v.32, n.1, p.102-119, 1996.

SILVA, C. S. Medidas e avaliação em educação. Petrópolis: Vozes, v. 2, 1992.

SILVEIRA, F. L. Coeficiente Beta: estimativa do Coeficiente de Fidedignidade de uma variável compósita. Educação e Seleção, n. 11, p. 105-108, 1985.

SILVEIRA, F. L. Validação de testes de lápis e papel. In: MOREIRA, M. A.; SILVEIRA, F. L. (Org.). Instrumentos de pesquisa em ensino e aprendizagem. Porto Alegre: EDIPUCRS, 1993.

SILVEIRA, F.L;; MOREIRA, M.A. e AXT, R. Validação de um teste para detectar se o aluno possui a concepção newtoniana sobre força e movimento. Ciência e Cultura, 38(12): 2047 - 2055, 1986.

TALIM, S. L. A atitude no ensino de Física. Caderno Brasileiro de Ensino de Física, v. 21, n. 3, p. 313-324, 2004.

VIANNA, H. M. Testes em Educação. São Paulo: IBRASA S.A., 220p. 1976.

WÖRNER, C. H. Simplemente: el plano inclinado. Revista Brasileira de Ensino de Física, v. 34, n. 2, p. 1-5, 2012. 